\title{
PHYSICAL TRAITS OF VAGINAL MUCUS DISCHARGE AND THEIR RELATIONS TO CONCEPTION RATE OF EGYPTAIN BALADI COWS
}

\author{
A. I. Damarany \\ Department of Animal and Poultry Production, Faculty of Agriculture and Natural Resources, Aswan \\ University, Egypt
}

Received: 15/03/2019 Accepted: 7/4/2020

\section{SUMMARY}

The current research aimed to study the conception rate of Egyptian native cows as influenced by vaginal mucus discharge (VMD). Forty cows were used in the experiment and were followed up after two-week postpartum. Vaginal mucus discharges were divided into three categories according to transparency (transparent, cloudy and dirty), viscosity (thin and thick) or $\mathrm{pH}(7-7.5,7.5-8$ and $>8)$. The results indicated that the percentage of cows that conceived which have transparent vaginal mucus discharge (VMD) during estrus were significantly $(P<0.05)$ higher $(73.3 \%)$ compared with cows which have cloudy and dirty vaginal mucus $(40$ and $20 \%)$, respectively. The percentage of cows that conceived which have thin vaginal mucus during estrus was significantly $(P<0.05)$ higher $(87.5 \%)$ compared to those cows which have thick vaginal mucus $(25 \%)$. The conception rate was significantly $(P<0.05)$ higher $(78.6 \%)$ in cows which have vaginal mucus pH level at estrus $>8$ compared with those cows which had vaginal mucus $p H$ value ranging from 7 to 8 . No significant difference in plasma progesterone concentrations during estrus in cows which have different vaginal mucus $p H$ in pregnant and non-pregnant baladi cows. However, concentrations of estradiol-17 $\beta d$ uring estrus in pregnant cows were significantly $(P<0.05)$ higher than non-pregnant cows. Concentration of estradiol-17 $\beta$ at estrus was significantly $(P<0.05)$ higher in cows which have strong estrus intensity expression compared with cows having weak estrus intensity expression. In conclusion, the results clarified that the cows, which had vaginal mucus discharge (VMD): transparent, thin, and pH value at estrus $>8$ recorded higher conception rate. Estradiol-17 $\beta$ concentration was significantly $(P<0.05)$ higher during estrus period in cows, which displayed high estrus intensity.

\section{Keywords: Physical traits, vaginal mucus discharge, Egyptian Baladi cows}

\section{INTRODUCTION}

Vaginal mucus discharge is considered a good indicator of reproductive health and potential fertility status of livestock (Tsiligianni et al., 2001 and Jeong et al., 2010). Kumar et al. (2017) stated that the color of vaginal mucus discharge was associated with several reproductive problems in cattle and buffalo. Physical properties of vaginal mucus discharge have direct bearing on the fertility status of the animals (Panchal et al., 1994 and Rangnekar et al., 2002). Many researchers investigated the relationships between properties of cervical mucus during estrus phase and conception rate in cattle (Madkar et al., 2015, Mellado et al., 2015 and Bernardi et al., 2016). Cervical mucus properties as an indicator of the female hormonal condition also play a vital role in conception rate (Benbia et al., 2011). Several authors suggested a high association between color of vaginal mucus and conception rate in cows (Lim et al., 2014, Bhat et al., 2015 and Parikh et al., 2018). Recently Hay et al. (2019) showed that abnormal cervical mucus discharge was associated with significantly decreased pregnancy rate in cows. In addition, Gautam et al. (2010) found that cows, which had cloudy vaginal mucus at mating, had lower conception rate compared with other cows.
Bhat et al. (2015), Bernardi et al. (2016) and Siregar et al. (2019) reported that there was a relationship between viscosity of vaginal mucus discharge and conception rate in cows. Ningwal et al. (2018), Kumar et al. (2019) and Hanumant et al. (2019) stated that $\mathrm{pH}$ of vaginal mucus discharge affected the conception rate in cows. Atkins et al. (2010), Perry et al. (2014) and Mogheiseh et al. (2019) found a positive relationship between estradiol-17 $\beta$ concentrations and intensity of estrus sings expression in cows. The current investigation was carried out to determine the effect of vaginal mucus discharge characteristics during estrus phase on conception rate of Baladi cows.

\section{MATERIALS AND METHODS}

\section{Climatic conditions and farm location:}

The study was carried out in animal farm located in Kom Ombou area $\left(32^{\circ}, 31^{\prime} 2^{\prime \prime}\right.$ "East and 22, 28' 09" North), Aswan Governorate. The animals were kept in traditional farm condition under semi shade system. Aswan Governorate climate is famous for higher ambient temperature and lower relative humidity especially during the hot season. Table (1) illustrates the average of the ambient temperature, relative humidity and temperature humidity index 
during the experimental period. The temperature humidity index (THI) was estimated according to the formula proposed by Mader et al. (2006):
Temperature-humidity index $(\mathrm{THI})=0.8 \mathrm{x}$ ambient temperature $+[(\%$ relative humidity $) 100) \times$ (ambient temperature -14.4$)]+46.4$

Table 1. The ambient temperature $\left({ }^{\circ} \mathrm{C}\right)$, relative humidity (RH \%) and temperature humidity index (THI) during the experimental period

\begin{tabular}{|c|c|c|c|c|}
\hline \multirow{3}{*}{ Months of calving } & \multicolumn{2}{|c|}{ Average } & Average & \multirow[t]{3}{*}{ TH } \\
\hline & Ambient & e $\left({ }^{0} \mathrm{C}\right)$ & \multirow[t]{2}{*}{ Relative humidity (RH \%) } & \\
\hline & Min & Max & & \\
\hline November & 20.4 & 31.3 & 18 & 74.5 \\
\hline December & 16.1 & 28.3 & 21 & 70.5 \\
\hline January & 13.2 & 21.2 & 22 & 64.9 \\
\hline February & 15.9 & 24.2 & 23 & 68.1 \\
\hline March & 18.3 & 32.2 & 20 & 75.8 \\
\hline April & 20.1 & 34.0 & 17 & 76.9 \\
\hline
\end{tabular}

\section{Management and feeding of herd:}

Forty Baladi cows were used in the current work. Cow's parity ranged between $2^{\text {nd }}$ and $6^{\text {th }}$. The averages of age $5.98 \pm 2.31$, years and body weight were $371.72 \pm 13.91, \mathrm{~kg}$, respectively, at calving. Animals were fed on Barseem Higaze (Alfa-Alfa) alongside the concentrate ration and hay wheat was offered during the experimental period.
Forty Baladi cows were divided according to transparency (transparent, cloudy and dirty), viscosity (thin and thick) or $\mathrm{pH}(7-7.5,7.5-8$ and $>8$ ) of vaginal mucus. The experimental animals calved during the interval from November to April and were followed up for two-week post-partum. Table (2) clarifies the classification of zones based on THI values in cattle with THI model according to Samal (2013).

\section{Experiment design:}

Table 2.Classification of zones based on THI values in cattle with THI model according to (Samal, 2013)

\begin{tabular}{lll}
\hline THI & Stress level & Response of cattle \\
\hline$<72$ & Non & Non-noticeable \\
$72-79$ & Mild & $\begin{array}{l}\text { Dairy cows will adjust by seeking shade, increasing respiration rate and dilation } \\
\text { of the blood vessels. } \\
\end{array}$ \\
& The effect on milk production will be minimal. \\
\hline
\end{tabular}

\section{Heat detection and diagnosis of pregnancy:}

Daily visual observation for cows were performed for heat detection in the morning at 6:0 am. and 6:0 $\mathrm{pm}$, for sexual behavior signs display. The cows were naturally mated when exhibited standing symptoms of heat. Rectal palpation was used (60 days postmating), to diagnose the established pregnancy as described by Arthur (1964).

\section{Estrus intensity:}

According to display, the estrus sings during the estrus phase, the cows were classified into two categories: strong estrus intensity expression, these cows, which appeared $\geq 3$ estrus signs at least during the estrus and weak estrus intensity expression, these cows, which appeared one estrus sign only during the estrus phase.

Conception rate: calculated as the percentage of cows, which conceived from the first mating postpartum

Conception rate $=($ Number of pregnant cows $/$ Total number of mated cows ) x 100

\section{Collection of vaginal mucus:}

Samples of vaginal mucus were collected from all cows immediately before mating. Vulva of the cow was washed by water and iodine solution $10 \%$ concentration before the collection. Plastic syringe (10ml) was used to withdraw the mucus from the vagina. The mucus was placed in transparent glass tubes.

\section{Measurement of vaginal mucus traits:}

Immediately, after the collection of vaginal mucus, they were examined according to Lim et al. (2014) classification as follows: vaginal mucus color (transparent, cloudy and dirty), and consistency (thin and thick). The $\mathrm{pH}$ was estimated using $\mathrm{pH}$ Merck paper by $0-14$ indicators. The $\mathrm{pH}$ paper was dipped into the vaginal mucus. The alteration in the color of the paper is compared to the attached standard value.

\section{Blood samples collection and hormones assay:}

Blood samples $(10 \mathrm{ml})$ were collected from cows at estrus, after mating in heparinized tubes from the jugular vein. The blood samples were centrifuged at $3000 \mathrm{rpm}$ for 20 minutes for plasma harvesting. Plasma was separated and stored at $-18^{\circ} \mathrm{C}$ until the time of analysis. Progesterone (P4) and estradiol-17 $\beta$ $\left(\mathrm{E}_{2}\right)$ hormone were determined using radioimmunoassay kit (Immunotech, France). Progesterone and estradiol-17 $\beta$ sensitivity values were reported to be $0.03 \mathrm{ng} / \mathrm{ml}$ and $4.0 \mathrm{pg} / \mathrm{ml}$, respectively according to manufacturer information. Intra as say variation coefficient was $7.4 \%$ and $12.7 \%$ 
for progesterone (P4) and estradiol-17 $\beta$ ( $\left.\mathrm{E}_{2}\right)$, respectively.

\section{Statistical analysis:}

The statistical design included one factor (effect of color (transparent, cloudy and dirty), consistency (thin and thick) or $\mathrm{pH}$ (7-7.5, 7.5-8 and >8) of vaginal mucus on conception rate). Chi Squire was used to test the significance of the percentage values. Statistical analysis was carried using software (SAS, 2002). The following model was used:

$$
\mathbf{Y}_{\mathbf{i j}}=\boldsymbol{\mu}+\mathbf{T}_{\mathbf{i}}+\mathbf{e}_{\mathbf{i j}}
$$

Where:

$\mathbf{Y}_{\mathbf{i j}}=$ the observation trait

$\boldsymbol{\mu}=$ overall mean

$\mathbf{T}_{\mathbf{i}}=$ the fixed effect of color (transparent $=1$, turbid $=2$ and dirty $=3$ ) or consistency (thin=1 and thick=2) or $\mathrm{pH}(7-7.5=1,7.5-8=2$ and $>8=3)$

$\mathbf{e}_{\mathbf{i j}}=$ experimental error

Duncan's Multiple Range test (Duncan, 1955) was used to test the significance of the differences between means.

\section{RESULTS AND DISCUSSION}

Vaginal mucus transparency during estrus and conception rate in Egyptian Baladi cows

Table (3) indicated that the percentage of cows that conceived had transparent vaginal mucus (VM) during estrus increased by $73.3 \% \quad(P<0.05)$ compared with those cows which had cloudy and dirty vaginal mucus. Similar results were reported by Lim et al. (2014) who found that the conception rate was $67.3 \%$ for dairy cows that had transparent vaginal mucus and Bhat et al. (2015) found that the conception rate was $94.1 \%$ for cows that had transparent vaginal mucus and reported similar trend. In addition, Mellado et al. (2015) suggested that the conception rate from the first service with transparent mucus was higher $(31.9 \%)$ than turbid mucus $(22.3 \%)$ in cows. Parikh et al. (2018) reported that cows with clear mucus had higher conception rate.
Senosy et al. (2012) found that postpartum first service conception rate in dairy cows having abnormal vaginal mucus discharge was significantly ( $\mathrm{p}<0.01)$ lower than those cows having normal vaginal mucus discharge (2.4\% vs. $30.2 \%)$ during the early weeks postpartum. Loeffler et al. (1999) reported that clear cervical mucus discharge at artificial insemination was positively, correlated with increased first service conception rate. LeBlanc et al. (2002) reported that the first service conception rate was higher in dairy cows with normal vaginal discharge (37\%) compared to those with abnormal vaginal contents $(29 \%)$ during postpartum period. Mahmoudzadeh et al. (2001) showed that the conception rate was significantly $(P<0.05)$ higher $(38.3 \%)$ in the normal vaginal discharge than that of the abnormal group $(27.9 \%)$ in cows. Sharma and Tripathi (1987) suggested that there was a great influence of the nature of cervical mucus on spermatozoa activity in the female reproductive duct. Verma et al. (2014) showed that higher conception rate of $41.3 \%$ in animals, which had clear cervical mucus than cloudy $14.3 \%$ in buffaloes. Bernardi et al. (2016) suggested that the conception rate was higher $(70 \%)$ in Holstein cows, which had transparent cervical mucus than opaque cervical mucus (30\%). Lopez-Gaius et al. (1993) stated that color of cervical mucus is considered one of the important factors which affects on sperm penetration and conception however, turbid mucus arrested sperm motility in cows. Hay et al. (2019) showed that abnormal cervical mucus discharge associated with significantly decreased in the pregnancy rate in cows. Murugavel and López-Gatius (2009) reported that cervical mucus appearance indicated good sexual health and as sociated with a higher conception rate in cows. Gautam et al. (2010) found that cows, which had cloudy vaginal mucus at artificial insemination, had lower conception rate compared with another cows.

Table 3. Effect of vaginal mucus (VM) transparency during estrus on the conception rate of Egyptian Baladi cows

\begin{tabular}{|c|c|c|c|}
\hline \multirow[t]{2}{*}{ Items } & \multicolumn{3}{|c|}{ Vaginal mucus transparency } \\
\hline & transparent & cloudy & dirty \\
\hline Total number of cows & (30) & (5) & (5) \\
\hline No. of pregnant cows & 22 & 2 & 1 \\
\hline$\%$ of pregnant cows ${ }^{1}$ & $73.3^{\mathrm{a}}$ & $40^{\mathrm{b}}$ & $20^{c}$ \\
\hline No. of non-pregnant cows & 8 & 3 & 4 \\
\hline$\%$ of non-pregnant cows ${ }^{1}$ & $26.7^{\mathrm{a}}$ & $60^{\mathrm{b}}$ & $80^{c}$ \\
\hline
\end{tabular}

1-Conception rate calculated from post-partum first service

a,b,c: values within the same row having different superscripts are significantly at $(\mathrm{P}<0.05)$.

Vaginal mucus viscosity during estrus and conception rate in Egyptian Baladi cows:

Table (4) illustrated the percentage of cows that conceived which had thin vaginal mucus during estrus was significantly $(P<0.05)$ higher $87.5 \%$ compared to those with thick vaginal mucus. Similar results were found by Lim et al. (2014) they found that higher $(P<0.10)$ conception rates $81.8 \%$ in cows had thin cervical mucus than thick $18.2 \%$ in dairy cattle. Similar trend showed by Bhat et al. (2015) who found the conception rate was $88.2 \%$ of cows, which had thin vaginal mucus compared with cows, which had thick vaginal mucus $11.8 \%$. Bernardi et al. (2016) stated that cows with thin and clear vaginal mucus had higher $(65 \%)$ pregnancy rate compared with those had thick vaginal mucus (40\%). Verma et 
al. (2014) reported that the conception rate in Murrah buffaloes, which had thin and moderate cervical mucus was higher $74.2 \%$ compared with thick cervical mucus (11.1\%). Siregar et al. (2019) stated that the conception rate was higher $(100 \%)$ in aceh cattle, which had thin cervical mucus compared with thick cervical mucus 20\%. Rutllant et al. (2005) suggested that during follicular phase the rheological properties of cervical mucus were more copious, watery and less viscous which assisted the transport of spermatozoa in the female reproductive tract. Bernardi et al. (2016) showed that the success rates of artificial insemination in Holstein cows can be classified according to cervical mucus viscosity (9,
30 and $61 \%$ ) for cows with thick, moderate and thin cervical mucus respectively. Rangnekar et al. (2002) and Layek et al. (2013) stated that coiled mucoproteins and reduced penetration and progressive movement of sperm maybe one of vital causes of lower conception rate in thick cervical mucus in Holstein Friesian and Zebu cattle. Siregar et al. (2019) showed that total protein content was 8.2, 9.75 and $9.48(\mathrm{~g} / \mathrm{dL})$ in thin, moderate and thick cervical mucus. The mucoprotein leads to reduce sperm penetration and prevent progressive movement of sperm, which causes a lower conception rate in cows with thick cervical mucus.

Table 4. Effect of vaginal mucus viscosity during estrus on the conception rate of Egyptian Baladi cows

\begin{tabular}{|c|c|c|}
\hline \multirow[t]{2}{*}{ Items } & \multicolumn{2}{|c|}{ Vaginal mucus viscosity } \\
\hline & Thin & thick \\
\hline Total number of cows & (32) & (8) \\
\hline No. of pregnant cows & 28 & 2 \\
\hline$\%$ of pregnant cows ${ }^{1}$ & $87.5^{\mathrm{a}}$ & $25^{\mathrm{b}}$ \\
\hline No. of non-pregnant cows & 4 & 6 \\
\hline$\%$ of non-pregnant cows ${ }^{1}$ & $12.5^{\mathrm{a}}$ & $75^{\mathrm{b}}$ \\
\hline
\end{tabular}

1-Conception rate calculated from post-partum first service,

a,b: values within the same row having different superscripts are significantly at $(\mathrm{P}<0.05)$.

Vaginal mucus pH level during estrus and conception rate in Egyptian Baladi cows

Table (5) clarified that the conception rate was significantly $(P<0.05)$ higher $(78.6 \%)$ in cows which had vaginal mucus $\mathrm{pH}$ level at estrus $>8$ compared with those cows with vaginal mucus $\mathrm{pH}$ level ranging between 7 to 8 . The current result corresponds with that reported by Ningwal et al. (2018) who found that the conception rate was higher $67.5 \%$ in crossbred cows that had vaginal mucus $\mathrm{pH}$ of 8.14 than those cows with vaginal mucus $\mathrm{pH}$ of 7.46. Verma et al. (2014) reported that conception rate was higher $42.2 \%$ in Murrah buffaloes, which had vaginal mucus $\mathrm{pH}$ level at estrus ranging between (7.5 to 8) compared with those cows with vaginal mucus $\mathrm{pH}$ value ranging between ( 7 to 7.5 ) $25 \%$. Siregar et al. (2019) reported that pregnancy rate was $100 \%$ in Aceh cattle when $\mathrm{pH}$ level of cervical mucus was ranged from 7 to 8 . Kumar et al. (2019) suggested that the vaginal mucus $\mathrm{pH}$ was $8.42 \pm 0.09$ and $8.72 \pm 0.22$ in conceived and non-conceived crossbred cows respectively. Dodamani et al. (2010) suggested that $\mathrm{pH}$ levels of cervical mucus during the estrus were around (8.83-8.91) in Deoni cows. Modi et al.
(2011) found that the $\mathrm{pH}$ levels of cervical mucus of fertile cows ranged from (7.3 to 9.1) in Kankrej cows. Bennur et al. (2004) and Rathod (2016) reported that the mean $\mathrm{pH}$ value of cervical-vaginal mucus in conceived cows was $(8.13 \pm 0.07)$ and $(8.45 \pm 0.11)$, respectively. Hafez and Hafez (2000) suggested that the increased acidity or alkalinity in cervical mucus could weak sperm motility and lead to fertilization failure. Predojevic et al. (2007) suggested that the $\mathrm{pH}$ of cervical mucus is considered one of the main factors to determine the success of pregnancy on livestock because cervical mucus is the transport medium for sperm in the reproductive tract in female. Branigan and Larry (2008) and Agarwal et al. (2008) stated that the pH of $7.0-8.5$ is optimal level, which supports sperm viability and motility, while $\mathrm{pH}$ below six lead to the weak motility of sperm. Siddiquee (2006) and Zaman et al. (2013) found that the mean $\mathrm{pH}$ value of cervical-vaginal mucus in non- conceived cows was $(7.40 \pm 0.09$ and $7.95 \pm 0.09)$. In a recent report, Hanumant et al. (2019) suggested that mean $\mathrm{pH}$ values in cervical mucus of conceived and non-conceived cows were $(8.30 \pm 0.11)$ and $(7.76 \pm 0.12)$, respectively.

Table 5. Effect of vaginal mucus pH level during estrus on the conception rate of Egyptian Baladi cows

\begin{tabular}{lccc}
\hline Items & \multicolumn{2}{c}{$\mathrm{pH}$ level } & $>8$ \\
\cline { 2 - 4 } & $7-7.5$ & $7.5-8$ & $(28)$ \\
\hline Total number of cows & $(4)$ & $(8)$ & 22 \\
No. of pregnant cows & 1 & 5 & $78.6^{\mathrm{c}}$ \\
$\%$ of pregnant cows & & $62.5^{\mathrm{b}}$ & 6 \\
No. of non-pregnant cows & $25^{\mathrm{a}}$ & 3 & $21.4^{\mathrm{c}}$ \\
\hline of non-pregnant cows & 3 & $37.5^{\mathrm{b}}$ & \\
\hline
\end{tabular}

1-Conception rate calculated from post-partum first service

a,b,c: values within the same row having different superscripts are significantly at $(\mathrm{P}<0.05)$. 
Progesterone, estradiol-17ßconcentrations in blood plasma and pH of vaginal mucus during estrus of pregnant and non-pregnant Egyptian Baladi cows

Table (6) indicated no significant $(P<0.05)$ difference in plasma progesterone concentrations during estrus in the cows which had different $\mathrm{pH}$ in pregnant and non-pregnant Baladi cows. However, concentrations of estradiol-17 $\beta$ in pregnant cows were significant $(P<0.05)$ higher than in nonpregnant Baladi cows Table (6). The present finding agreed with that stated by Bernardi et al. (2016) who found lower concentrations of progesterone and higher concentrations of estradiol-17 $\beta$ in pregnant cows which had cervical mucus $\mathrm{pH}$ (7.6) compared to non- pregnant cows which had cervical mucus $\mathrm{pH}$ (7.2) in Holstein cows. Rolfs et al. (2005) reported that the hormonal alteration during the per-estrus period affected on the estrus behavior expression. Tsiligianni et al. (2011) and Layek et al. (2013) suggested that traits of cervical mucus were converting according to ovarian hormones level secreted during estrus, this cervical mucus can act either as a mechanical barrier to sperm motion, or as a facilitator of sperm to arrive the site of fertilization in reproductive tract in the female. Predojevic et al. (2007) reported that the cow onset estrus, a time when there is lack or recession of the corpus luteum, concentration of progesterone are in lower levels and full follicular development. Mullins and Saacke (1989) and Pluta et al. (2011) stated that physical and chemical changes in cervical mucus during the estrus cycle related to fluctuations in sex steroid hormones.

Table 6. Progesterone (ng /ml), estradiol-17ß (pg/ml) concentrations (mean $\pm \mathrm{SE}$ ), in blood plasma and pH of vaginal mucus during estrus of pregnant and non-pregnant Egyptian Baladi cows

\begin{tabular}{lccc}
\hline Items & $\mathrm{pH}$ & $\mathrm{P} 4(\mathrm{ng} / \mathrm{ml})$ & $\mathrm{E} 2(\mathrm{pg} / \mathrm{ml})$ \\
\hline Pregnant cows & $7-7.5$ & $0.22 \pm 0.02^{\mathrm{a}}$ & $32.4 \pm 4.3^{\mathrm{a}}$ \\
& $7.5-8$ & $0.24 \pm 0.03^{\mathrm{a}}$ & $33.2 \pm 3.1^{\mathrm{a}}$ \\
Non-pregnant cows & $>8$ & $0.27 \pm 0.04^{\mathrm{a}}$ & $37.5 \pm 2.4^{\mathrm{a}}$ \\
& $7-7.5$ & $0.27 \pm 0.01^{\mathrm{a}}$ & $12.1 \pm 2.3^{\mathrm{b}}$ \\
& $7.5-8$ & $0.21 \pm 0.02^{\mathrm{a}}$ & $18.1 \pm 1.3^{\mathrm{b}}$ \\
\hline
\end{tabular}

$a, b:$ values within the same column having different superscripts are significantly at $(P<0.05)$.

\section{Estradiol-17ß concentration and estrus intensity expression in Egyptian Baladi cows}

Table (7) showed that concentration of estradiol$17 \beta$ at estrus was significantly $(\mathrm{P}<0.05)$ higher in cows which had high estrus intensity expression compared with those cows which have weak estrus intensity expression. The present result clarified that there was a positive relationship between estrus intensity expression and concentrations of estradiol$17 \beta$ during estrus. The current finding corresponded with that reported by Lyimo et al. (2000) who found higher correlation between the visual sings of estrus and estradiol-17 $\beta$ concentrations. Similar trend was observed by SáFilho et al. (2009) and Atkins et al. (2010) who suggested that a significant positive correlation between estradiol concentration and high incidence of estrus expression. In addition, Jinks et al. (2013) and Perry et al. (2014) found a positive relationship between peak concentrations of estradiol, and exhibited intensity of estrus in cows. Rolfs et al. (2010) reported that positive association between the conception rate, higher concentrations of estradiol$17 \beta$ and estrus expression in cows. Mogheiseh et al. (2019) suggested that low concentration of estradiol$17 \beta$ at mating were the main causes for the occurrence of repeat breeding syndrome in dairy cows. Ozturk and Demir (2010) reported that estradiol-17 $\beta$ at artificial insemination plays a vital role in establishing the timing of uterine receptivity. Pre-ovulatory concentrations of estradiol-17 $\beta$ influenced sperm transport, embryo survival and the uterine environment (Miller, 1976, Hawk, 1983 and Perry and Perry, 2008).

Table 7. Estradiol-17 $($ mean $\pm \mathrm{SE})(\mathrm{pg} / \mathrm{ml})$ concentration and estrus intensity expression in thirty Egyptian Baladi cows

\begin{tabular}{lcc}
\hline Estrus intensity & No. of cows & Estradiol-17 $\beta(\mathrm{pg} / \mathrm{ml})$ \\
\hline Weak estrus intensity expression & 15 & $15.4 \pm 1.3^{\mathrm{a}}$ \\
High estrus intensity expression ${ }^{2}$ & 15 & $32.7 \pm 1.1^{\mathrm{b}}$ \\
\hline a, b: values within the same column having different superscripts are significantly at $(\mathrm{P}<0.05), 1$-Weak estrus intensity \\
expression: These cows, which appeared one sign only during the estrus. 2-High estrus intensity expression: These cows, \\
which appeared $\geq 3$ signs at least during the estrus.
\end{tabular}

\section{CONCLUSION}

The results clarified the cows, which had vaginal mucus discharge (VMD): transparent, thin, and $\mathrm{pH}$ value at estrus $>8$ recorded higher conception rate. Estradiol-17 $\beta$ concentration was significantly $(P$
$<0.05)$ higher during estrus period in cows, which displayed high estrus intensity. 


\section{REFERENCES}

Agarwal, A., F. M. Bragais and E.Sabanegh, 2008. Assessing sperm function. Urol. Clin. North. Am., 35(2): 157-171.

Arthur, G. H., 1964. Method of rectal examination. Wright's Vet. Obs., 4: 71-80.

Atkins. J. A., M. F. Smith, K. J. Wells and T.W. Geary, 2010. Factors affecting preovulatory follicle diameter and ovulation rate after gonadotropin-releasing hormone in postpartum beef cows. Part I: Cycling cows. Journal Animal Sci., 88:2300-2310.

Bernardi, S., A.Rinaudo, and P. Marini, 2016. Cervical mucus characteristics and hormonal status at insemination of Holstein cows. Int. J. Vet. Res., 17(1): 45-49.

Benbia, S., A.Kalla, M. Yahia, K. Belhadi, and A.Zidani, 2011. Enzymes activity in bovine cervical mucus related to the time of ovulation and insemination. International Journal of Biological, Bimolecular, Agricultural, Food and Biotechnological Engineering. 5: 664-666.

Bennur, P.C., S. S.Honnapaggol, and M. K.Tandle, 2004. Effect of physico-chemical properties of cervicovaginal mucus on fertility in cow. The Indian Veterinary Journal, 81(9): 1069.

Bhat, F. A., H. K. Bhattacharyya, M. R. Fazili, S. A. Hussain and M. Z. Khan. 2015. Studies on estrualcervical mucus of repeat breeding cows with special reference to ovulatory disturbances and genital infection. Theriogenology Insight, 5(2): 113-123.

Branigan, R. E.and I. L. Larry, 2008. Sperm transport and capacitation. London. Global Library of Women's Medicine. United of Kingdom.

Dodamani, M.S., K.Mohteshamuddin, S. D. Awati, M. K. Tandle, and S. S. Honnappagol, 2010.Evalaution of pre and post artificial insemination effect of $\mathrm{GnRh}$ hormone on conception of repeat breeder dairy cows. Veterinary World, 3(5): 209-211

Duncan, D. B., 1955. Multiple ranges and multiple F. Test. Biometrics, 11:1-24.

Gautam, G., T.Nakao, K. Koike, S. T. Long, M. Yusf, R. M.Ranasinghe, and A. Hayashi, 2010. Spontaneous recovery or persistence of postpartum endometritis and risk factors for its persistence in Holstein cows. Theriogenology,73:168-179.

Hafez, B. and E.S.E. Hafez, 2000. Reproduction in Farm Animals. 7th Ed. Lippincott William and Wilkins. Philadelphia.

Hanumant, D., R. P.Tiwari, A. K.Chaturvedani, Dilip Paikra, Choodamani Chandrakar and Praveen Ratre, 2019. Analys is of corporeal characteristics of cervico-vaginal mucus in cows. The Pharma Innovation Journal, 8(3): 261-264.

Hawk, H. W., 1983.Sperm survival and transport in the female reproductive tract. Journal Dairy Science., 77:2738-2744.
Hay, M. J., A. J. Gunn, A.Abuelo and V. J. Brookes, 2019. The effect of abnormal reproductive tract discharge on the calving to conception interval of dairy cows. Front. Vet. Sci., 6:374.

Jeong, G.Y., S. J. Park, N. H. Kim, K. SBaek, B. S.Jeon, H. J. Lim, T.Y. Her, K. S. Ki, G. S.Lee,S. Y. Kang, H. J. Lee, W. K.Chang and H. S. Kim, 2010. Factors effecting on artificial insemination in multi-parturition cattle. J. Emb. Trans., 25(3): 155-159.

Jinks, E.M., M. F. Smith, J. A. Atkins, K. G. Pohler, G. A. Perry, M. D.Macneil, A. J. Roberts, R. C. Waterman, L. J. Alexander and T. W. Geary, 2013. Preovulatory estradiol and the establishment and maintenance of pregnancy in suckled beef cows. J Anim. Sci., 91:1176-85.

Kumar, A., S.Srivastava, S. K.Yadav, A. K.Yadav and V.SaurabhChaudhary, 2017. Physicochemical characteristics of cervical discharge in endometriticrepeat breeder cow. Int. J Pure App. Biosci., 5(3):821-831.

Kumar,A., S. Kumar, M.Shivhare, R.Aich, Vinita and Shailendra, 2019. Correlation of rheological properties of cervico: Vaginal with vaginal electrical impedance and fertility in repeat breeding crossbred cows. Journal of Entomology and Zoology Studies, 7(4): 790-793.

Layek, S., T.Mohanty, A. Kumaresan, K.Behera, and S. Chand,2013. Cervical mucus characteristics and periestrual hormone concentration in relation to ovulation time in Zebu (Sahiwal) cattle. Livest. Sci., 152: 273-281.

LeBlanc, S. J., T. F. Duffield, K. E. Leslie, K. G. Bateman, G. P. Keefe and J. S. Walton, 2002. Defining and diagnosing postpartum clinical endometritis and its impact on reproductive performance in dairy cows. J Dairy Sci., 85: 2223-2236.

Lim, H. J., J.K. Son, H.B. Yoon, K.S. Baek, T. K.Y.Sub Jung and E.G. Kwon, 2014. Physical properties of estrus mucus in relation to conception rates in dairy cattle. J. Emb. Trans., 29(2):157-161

Loeffler, S. H., M. J. De Vries, Y. H. Schukken, A. C. De Zeeuw, A. A. Dijkhuizen, F. M. De Graaf and A. Brand, 1999. Use of technician scores for body condition, uterine tone and uterine discharge in a model with disease and milk production parameters to predict pregnancy risk at first AI in Holstein dairy cows. Theriogenology, 52: 12671284.

Lopez-Gaius, F., J. Miro, I. Sebastian, A. Ibarz and J. Labernia, 1993. Rheological properties of the anterior vaginal fluid from the super ovulated dairy heifers at estrus. Theriogenology, 40:167-180.

Lyimo, Z. C., M. Nielen,W. Ouweltjes, T.A.M. Kruip, andF.J.C.M. Van-Eerdenburg, 2000. Relationship among estradiol, cortisol and intensity of estrous behavior in dairy cattle. Theriogenology, 53 (9):1783-1795. 
Mader, T. L., M.S. Davis, and T. Brown-Brandl, 2006. Environmental factors influencing heat stress in feedlot cattle. J. Anim. Sci., 84: 712-719.

Madkar, A.R., S. S.Lathwal, T. K.Mohanty, M. Abdullah and K.Santosh, 2015. Estrous confirmation on the basis of behavioral signs of intensity in crossbred cows. Ind. Vet. J., 92(6):6061.

Mahmoudzadeh, A. R., M. Tarahomi and H. Fotoohi, 2001. Effect of abnormal vaginal discharge at oestrus on conception rate after artificial insemination in cows.J Animal Sci., 72 (3):535-538.

Mellado, M., L. M. Lara, F.G.Veliz, M. Á.De Santiago, L.Avendaño-Reyes, C. Meza-Herrera and J. E. Garcia, 2015. Conception rate of artificially inseminated Holstein cows affected by cloudy vaginal mucus, under intense heat conditions. Pesq. agropec. bras., Brasília, 50 (6):492-498.

Miller, B.G. andN. W. Moore, 1976. Effect of progesterone and oestradiol on endometrial metabolism and embryo survival in the ovariectomized ewe. Theriogenology, 6 (6):636

Modi, L.C., B. N.Suthar, H. C. Nakhasi, V. K. Sharma and H. H.Panchasara, 2011. Physical characteristics of oestrual cervical mucus and conception rate in repeate breeder Kankrej cattle. International Journal for Agro Veterinary and Medical Sci., 5(4): 416-423.

Mogheiseh,A., M. Kafi,, N.Golestani, A.RoshanGhasrodashti, S.Nazifi and A.Mirzae, 2019. Follicular fluid composition of ovulatory follicles in repeat breeder Holstein dairy cows. Asian Pacific Journal of Reproduction, :124-131.

Mullins, J. K. and R.G.Saacke, 1989. Study of the functional anatomy of bovine cervical mucosa with special reference to mucus secretion and sperm transport. Anat. Rec., 225(2):106-17.

Murugavel, K. and F.López-Gatius, 2009. Newtonian behavior of the vaginal fluid as a risk indicator of reduced fertility in cows. Indian Vet. J., 86: 12881289.

Ningwal, D., Sant Prasad Nema1, Sudarshan Kumar1, Ameeta Kushwah2 and Madhu Shivhare, 2018. Rheologicalproperties of cerviovaginalmucusinrelationto fertility in crossbred cows and heifers. Int. J. Adv. Res., 6(6): 495500.

Ozturk, S. and R. Demir, 2010. Particular functions of estrogen and progesterone in establishment of uterine receptivity and embryo implantation. Histol His topathol, 25:1215-28.

Panchal, M.T., A.J. Dhami, H.J. Derashri and S.B. Kodagali, 1994. Biochemical attributes of cervico- vaginal mucus of repeat breeding buffaloes in relation to its physical, physiological and immunological properties. Indian J. Anim. Sci., 64(8): 830- 833.

Parikh, S. S., T. K. Patbandha, B. D.Savaliya, R.B. Makwana, R. J.Raval and P.S.Kapadiya, 2018. Association of estrous behaviour and cervical mucus properties with conception in Gir cows. Journal of Pharmacognosy and Phytochemistry, SP1: 310-314.

Perry, G. A. and B. L. Perry,2008. Effect of preovulatory concentrations of estradiol and initiation of standing estrus on uterine $\mathrm{pH}$ in beef cows. Domestic Animal Endocrinology, 34:333338.

Perry, G. A., O.L. Swanson, E.L. Larimore, B.L. Perry, G.D. Djira and R.A. Cushman, 2014. Relationship of follicle size and concentrations of estradiol among cows exhibiting or not exhibiting estrus during afixed-time AI protocol. Domestic Animal Endocrinology 48: 15-20.

Pluta, K., J. A. Irwin, C. Dolphin, L. Richardson, E. Fitzpatrick, M. E. Gallagher and et al., 2011. Glycoproteins and glycosidases of the cervix during the periestrous period in cattle. J Anim. Sci., 89(12):4032-42.

Predojevic, R. M., T.Petrujkic, T. B.Petrujkic, and M. N.Predojevic,2007. Influence of the ovarian hormones on the cervical mucus (biophysical properties) and sperm transport in relation to cow's conception rates. Lucr. Şt. Med. Vet. Timişoara., XL: 91-94.

Rangnekar, M. N., R. L.Dhoble, M. G.Gacche, M. V.Ingawale, A. G.Sawale, and J. M.Jadhav, 2002. Physical properties of oestrual cervical mucus in repeat breeding crossbred (Holstein Friesian) cows with reference to fertility. Indian J. Anim. Sci., 72(12): 1122-1124.

Rathod, V., 2016. Therapeutic efficacy of GnRH and hCG analogue in non-infectious repeat breeding crossbred cows. M.V.Sc Thesis (Department of Veterinary Gynaecology and Obstetrics), NanajiDeshmukh Veterinary Science University, Jabalpur (M.P).

Roelofs, J. B., F. J. C. M.Van Eerdenburg,N. M.Soede and B.Kemp,2005.Various behavioural signs of estrus and their relationship with time of ovulation in dairy cattle. Theriogenology, 63:1366-1377.

Roelofs, J., F. López-Gatius, R. H. F. Hunter, F.J. C. M. Van Eerdenburg and C. H.Hanzen, 2010. When is a cow in estrus? Clinical and practical aspects. Theriogenology, 74:327-344.

Rutllant, J., M. Lopez-Béjar, and F. LopezGatius,2005.Ultrastructural and rheological properties of bovine vaginal fluid and its relation to sperm motility and fertilization: A review. Reprod. Domest. Anim ., 40: 79-86.

SáFilho, O.G., M. Meneghetti, R. F. G. Peres, G. C. Lamb and J. L. M.Vasconcelos, 2009. Fixed-time artificial insemination with estradiol and progesterone for Bosindicus cows II: Strategies and factors affecting fertility. Theriogenology,72: 210-218.

Samal, L., 2013. Heat stress in dairy cows reproductive problems and control measures. International Journal of Livestock Research, $13: 14-23$. 
SAS, 2002. User's Guide: Statistics, Version 9.0 Edition. SAS Institute Inc., Cary, NC, USA.

Senosy, W., M.Uchiza, N. Tameoka, Y. Izaike and T.Osawa, 2012. Evaluation of reproductive tract infection during early post-partum period and its relationship with subsequent reproductive performance in high milk producing dairy cows. Reprod. Dom. Anim., 47: 203-207.

Sharma, V. K. and S. S.Tripathi, 1987. Physiochemical properties of cervical mucus in relation to conception in normal and repeat breeding crossbred cows. Ind. J. Anim. Repro., 8: 43-45.

Siddiquee, G.M., 2006. Association of some biochemical attributes of estrualcervico-vaginal mucus with the fertility status of crossbred cows. Indian Journal of Field Veterinarians, 2: 8-10.

Siregar, T. N., T. Armansyah, B. Panjaitan, G. Gholib, H. Herrialfian, A. Sutriana, Z. Abidin, M. A. Reynaldi, F.Razak, Y. Artaliani and Y. Yuswar, 2019. Changes in cervical mucus as an indicator of fertility in Aceh cattle.Adv. Anim. Vet. Sci., 7(4): 306-314.
Tsiligianni, T. H., A. Karagiannidis, P.Brikas, Ph.Saratsis, 2001. Physical properties of bovine cervical mucus during normal and induced by progesterone and/or PGF2alpha estrus. Theriogenology, 55:629-640.

Tsiligianni, Th., G. Amiridis, E. Dovolou, I.Menegatos, S.Chadio, D.Rizos, and A. Gutierrez-Adan, 2011. Association between physical properties of cervical mucus and ovulation rate in superovulated cows. Can. J. Vet. Res., 75: 248-253.

Verma, K.K., S. Prasad, A.Kumaresan, T. K.Mohanty, S. S.Layek, T. K.Patbandha and S. Chand, 2014. Characterization of physicochemical properties of cervical mucus in relation to parity and conception rate in Murrah buffaloes. Veterinary World, 7(7): 467-471.

Zaman, M.I., U. Sharma, S. Kumar, and S. Kumar, 2013. Studies on physical properties of cervical mucus of repeat breeding crossbred cows. Indian Journal of Animal Reproduction, 34(2): 6-12.

\section{الخصائص الطبيعية للمخاط المهبلى وعلاقتها بمعل الحمل فى الأبقار البلاية المصرية}

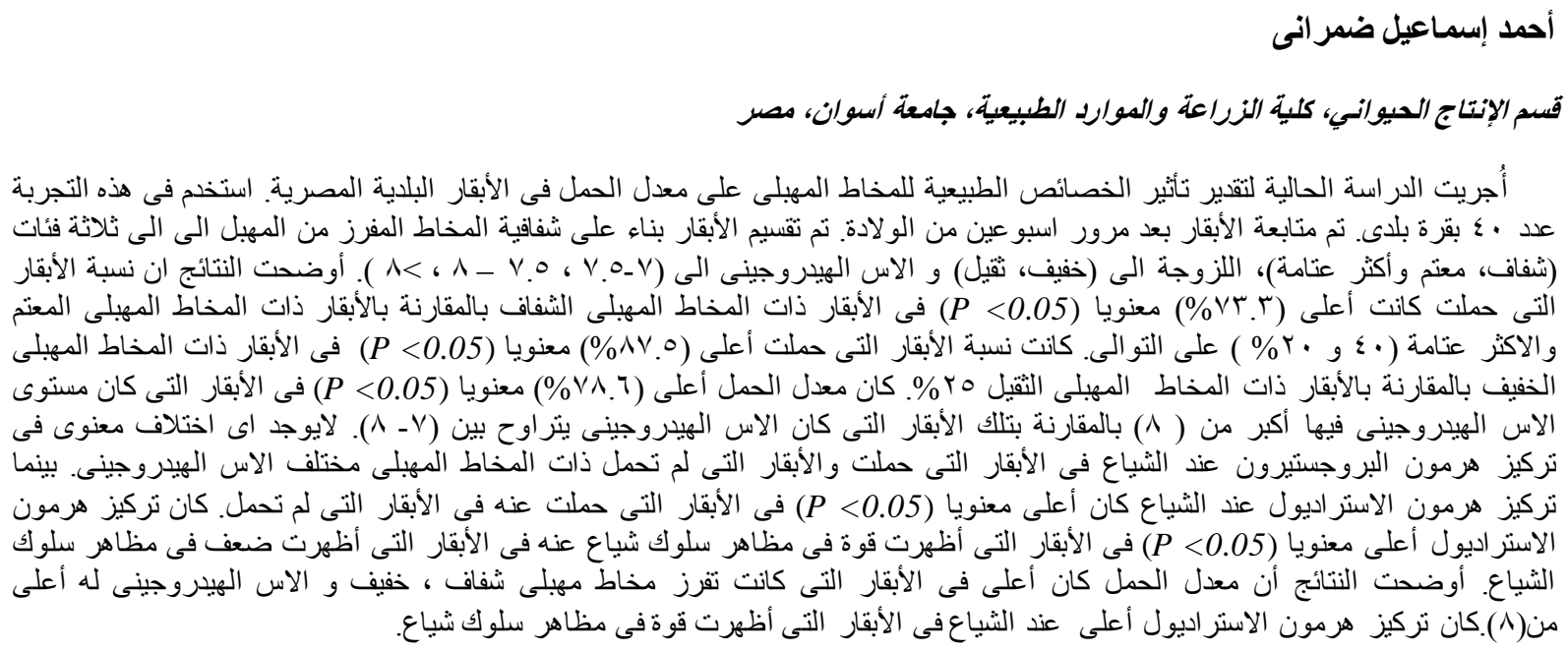

